\title{
Analysis of susceptibility of peat on its spontaneous heating and self-ignition properties
}

\author{
Marzena Półka ${ }^{1, *}$ \\ ${ }^{1}$ The Main School of Fire Service, Faculty of Fire Safety Engineering, 52/54 Slowackiego St., \\ 01-629 Warsaw, Poland
}

\begin{abstract}
The objective of the paper was to review and to assess the propensity of selected peat dusts to self-ignite. A comparison was carried out of the impact that the volume of dust storage exerts on values of the self-ignition temperature. The necessity of increasing peat share in generation of energy forced the investors to re-design or create from scratch a new technology. Due to differences between combustion of the fuel - biomass and coal - also the safety issues required a completely new approach. Therefore, this article presents factors that affect spontaneous heating and self-ignition of peat on its self-ignition properties when stored in bulk. The values of experimentally determined temperatures of selfignition for peat are included. The research was performed in compliance with methods specified in PN-EN 15188:2009. The were used three types of dusts having varying crushing levels and level acidity. Based on the analysis of results, it was determined that analysing the self-ignition tendency of the examined dusts is of informative nature and it can differ from the actual conditions prevailing when stockpiling the examined peat dusts.
\end{abstract}

\section{Introduction}

The phenomenon of self-heating, which can lead to self-ignition of materials, is dangerous in various branches of industry, e.g. in mining. Endogenous fires on peat or coal depots in power plants, which result from self-ignition of coal, are caused by oxidation that generates heat which is accumulated in the material and not carried away. Installations used for co-incineration of biomass or peat were designed for application of coal as a fuel. The necessity of increasing peat share in generation of energy forced the investors to re-design or create from scratch a new technology. Due to differences between combustion of the fuel - peat and coal - also the safety issues required a completely new approach. This article aims at evaluating the susceptibility of peat on its spontaneous heating and self-ignition properties. The research was conducted in compliance with the standard used for determination of self-ignition tendency in accumulated dusts acc. to PN-EN 15188:2009.

\footnotetext{
* Corresponding author: mpolka@sgsp.edu.pl
} 
During the research, limit temperatures between the self-ignition and spontaneous heating were determined for selected dusts when stored hot.

Explosive and ignition properties of the peat dust and coal dust used in power plants are very different. They depend, inter alia, on type and origin of a given fuel, granularity and moisture content. For peat, the parameters of explosion limits and flammability significantly depend on the percentage ratio of the components. Dust explosion hazard occurs in practically all the places where there is inflammable dust. Industrial dusts of specific granularity and concentration in the air and of specific ignition activation properties can create explosive atmosphere. Peat stored in power plants, e.g. as briquette, contains significant amount of dust, and it breaks up further while being transported on peat feeding lines. Dust clouds and deposits can form during such processes. When such a mixture starts to ignite, an explosion may occur, generating a pressure wave and a flame front that follows it. During such a phenomenon explosions often move over long distances, which is caused by convection of deposited dust by the pressure wave generated during explosion [9]. Combustible dusts pose a threat of explosion by forming a mixture of dust and air, and/or a layer of dust which can ignite as a result of self-heating, and then the ignited layer of dust can act as a source of subsequent explosions [6]. The risk of fire in the layer of dust, in relatively low temperatures, is connected with smouldering, glowing combustion and/or ignition of flame or hot surface. Before the above-mentioned phenomena occur, combustible dusts are most frequently subject to self-heating. Fire risk posed by the dusts is connected not only with the combustion itself, it also depends to a large degree on its location [3, 4]. Self-heating of peat dust, that precedes self-ignition, is the consequence of a series of chemical reactions, physical or biological processes that occur in the given material. Briquette peat is most susceptible to self-ignition (mostly stored in stockpiles), and it is followed by lignite (stored as briquette, briquette dust and in stockpiles). Oxidation is facilitated by adsorption of oxygen by peat (contain carbon), which results in generation of heat. When the heat of oxidation is not transmitted outside, temperature in the material will continue to rise, which may lead to ignition of peat in the pile. Wind plays an important role in the process of self-ignition. Research shows that selfignition of peat in stockpiles has happened most often on the windward direction [15]. The carbon oxidation process can be unnoticeable (smouldering or flame burning). The rate of carbon oxidation in peat is significantly affected by such factors as: peat fragmentation, contents of mineral substances in the peat, hygroscopic moisture, and carbon content. The greater the peat fragmentation, the higher the risk of self-ignition in the environment. Another parameter that has a great impact on self-ignition of peat is its content of hygroscopic moisture. Hygroscopic moisture in the process of self-heating is a negative factor, because the greater its content in carbon, the higher the risk of self-ignition. However, when there is too much water, susceptibility to self-ignition is reduced, because a lot of water evaporates and absorbs the heat generated during oxidation [7].

Self-ignition temperatures differ greatly depending on type of peat. The most frequently observed critical temperature for open stockpiles is $60-80^{\circ} \mathrm{C}$. The first visible effects of self-heating of peat is the drops of water vapour that settle as dew. When heat is carried away or the temperature does not reach or exceed the critical temperature, the process of self-heating will discontinue. At this stage methane, ethane, propane and hydrogen are released. In the last phase of self-heating, white smoke is released, which leads to selfignition of carbon in peat [15]. Self-heating can occur when heat-generating processes occur in the substance. In the case of solid bodies, material must be porous or loose. Selfheating is not possible if reactions take place only on the external surface of the material. Additionally, the substance must be subject to smouldering. According to Siemionov theory, self-heating is a process in which there has to be at least a balance between the generation of heat as a result of, for instance, chemical reactions, and the loss of heat due to 
cooling of the combustion system. Cooling most often takes place as a result of convection along the external edges of the volume in which self-heating occurs. The generated amount of heat depends on the volume of material, and the heat loss is proportional to its area. It was observed that the bigger the prism of stockpiled material, the easier it accumulates heat. The bigger the pile, the lower the self-ignition temperature, and the ambient temperature, e.g. of air, should be reduced to prevent from spontaneous ignition. If the material in which self-heating occurs fails to reach the self-ignition temperature, it will form a carbonized bulk inside. However, there will be no smouldering or flames on the surface. For most self-ignitable substances, oxygen in the air is necessary for chemical reactions.

\section{Experiment part}

\subsection{Description of tested dusts}

The tests have been conducted using three types of dusts having varying crushing levels, and namely:

- dust of peat bricks with grading of $\leq 100 \mu \mathrm{m}$,

- dust of de-acidified peat o $\mathrm{pH} 5-6.5$ and grading of $\leq 100 \mu \mathrm{m}$,

- dust of acidic peat with $\mathrm{pH} 3.5-4$ and grading of $\leq 100 \mu \mathrm{m}$.

Acidic peat for potting mixtures is a natural product of plant organic origin. The studied acidic peat belongs to a group of high peat species, the properties of which help enhance the subgrade structure, provide decay, and loosen and aerate the soil.

De-acidified peat for potting mixtures was an appropriately formulated mixture of high and low peat types, and it was additionally de-acidified with the use of chalk. The studied dust may be used to produce potting mixtures with an option of applying individual fertilisation.

The tested acidic peat and de-acidified peat was distributed by Tamark S.A., an entity operating in Kartoszyno. The tested dust of peat bricks is used quite widely, but its primary use is in grills, fireplaces, traditional coal furnaces, boiler stations in plants and in municipal boiler stations, heat power plants and heat and power generating plants. The tested peat bricks were sold by an entity called Bialenergo operating in Krupniki. The moisture content of peat dust was below $12 \%$.

The first stage of obtaining peat dust was grinding the material in ring-roller mill. Next, dust samples were prepared by screening through a vibrating sieve of defined standardized diameter. This guaranteed that the tested sample of dust contained grains of diameter not greater than the nominal sieve opening size.

\subsection{Description of test methods}

The susceptibility of selected peat dusts to self-heating and self-ignition was analysed with use of method compliant with PN-EN 15188:2007. The tests were carried out in a combustion chamber with a volume $115 \mathrm{~cm}^{3}$. The test consists in placing a dust sample in a basket with a known volume for the oven at the selected temperature and measuring the temperature in the middle of the basket.

Pursuant to PN-EN 15188:2007, there are two ways of telling if there was an ignition:

- when the temperature inside the tested sample exceeds the temperature of furnace by $60 \mathrm{~K}$ (curve B, Fig. 1),

- when the temperature inside the tested sample as a function of time reaches the inflection point, if this occurs above the furnace temperature (curve C, Fig. 1). 
The temperature of furnace for the final two tests must be set at such a value to ensure that the difference between the furnace temperature that does not result in ignition of the sample and the temperature of testing that causes ignition of the sample does not exceed $5 \mathrm{~K}$. When greater volumes are used to test hot storage, the difference between the ignition temperature and the temperature that does not cause ignition should not exceed $2 \mathrm{~K}$. The result of measuring self-ignition temperature should be rounded off down to the nearest integer.

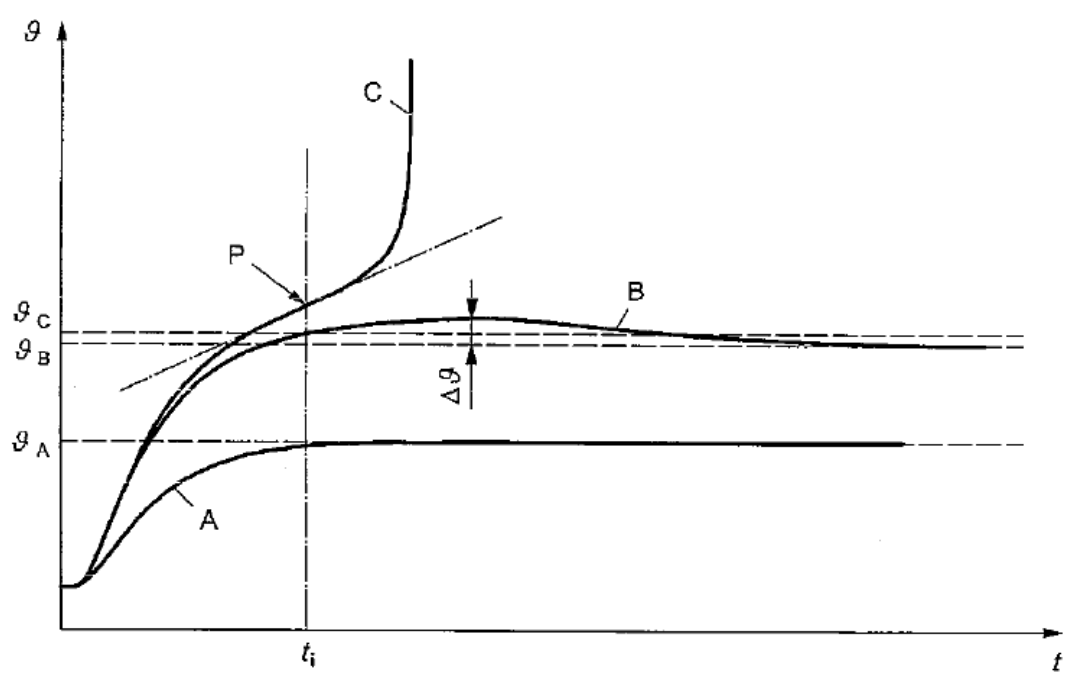

Fig. 1. Idealized temperature of the same volume dust samples (during a hot storage) in function time measurements - $\mathrm{P}$ - inflection point, $\mathrm{t}$ - duration of the study, $\vartheta$ - temperature of the dust or $\vartheta_{\mathrm{A}}, \vartheta_{\mathrm{B}}, \vartheta_{\mathrm{C}}$ temperature of the furnace[11].

During the test, metal baskets with two capacities were used:

1) basket $\mathrm{n} 1$ with a volume of $23 \mathrm{~cm}^{3}$,

2) basket $\mathrm{n} 2$ with a volume of $54.8 \mathrm{~cm}^{3}$.

A basket with a volume of $\mathrm{n} 1$ or $\mathrm{n} 2$ was weighed and the weight was tared. Then, peat dust was poured into it. Then, excess dust protruding over the upper edge of the basket was removed and the basket was weighed. The measurement results were recorded.

Then a basket was put into the heated oven with the tested dust. Two extreme thermocouples gave the temperature of the furnace, and the middle one placed inside the dust, gave its temperature. In order to ensure the inflow of fresh air, the inlet and outlet openings were left open. It also allowed the removal of thermal decomposition products and combustion. Temperature recording was carried out continuously. The test was carried out for each selected volume of the basket ( $\mathrm{n} 1$ and $\mathrm{n} 2$ ) and for each type of dust. Each time before the measurement, the dust was changed to a fresh sample. This made it possible to determine the lowest temperature at which the sample self-ignites and the highest temperature at which no inflammation occurred (curve A, Fig. 1).

The test was terminated when the temperature in the basket decreased (curve B on the graph (Figure 1) decreases) or when the temperature inside the sample increased by a minimum of $60 \mathrm{~K}$ compared to the furnace temperature.

Moisture content in the samples was determined in compliance with PN-EN 147743:2009. 


\section{Test results}

Table 1 shows self-ignition temperatures for individual types of dusts in specific volume.

Table 1. Self-ignition temperatures of tested dusts.

\begin{tabular}{|c|c|c|c|c|c|}
\hline $\begin{array}{l}\text { Type o the } \\
\text { dust }\end{array}$ & $\begin{array}{c}\text { Granulation } \\
{[\mu \mathrm{m}]}\end{array}$ & $\begin{array}{c}\text { The } \\
\text { volume of } \\
\text { basket } \\
{\left[\mathrm{cm}^{3}\right]}\end{array}$ & $\begin{array}{c}\text { Self-ignition } \\
\text { temperature } \\
{\left[{ }^{\circ} \mathrm{C}\right]}\end{array}$ & $\begin{array}{c}\text { Bulk } \\
\text { density } \\
{\left[\mathrm{g} / \mathrm{cm}^{3}\right]}\end{array}$ & $\begin{array}{c}\text { Humidity } \\
\text { of dust } \\
\text { [wt\%] }\end{array}$ \\
\hline \multirow{4}{*}{$\begin{array}{c}\text { dust of } \\
\text { peat } \\
\text { bricks, }\end{array}$} & \multirow{2}{*}{$\leq 100$} & 23 & 162 & 0.47 & \multirow{4}{*}{10.0} \\
\hline & & 54.8 & 156 & 0.46 & \\
\hline & \multirow{2}{*}{$\leq 500$} & 23 & 166 & 0.58 & \\
\hline & & 54.8 & 156 & 0.61 & \\
\hline \multirow{4}{*}{$\begin{array}{l}\text { dust of de- } \\
\text { acidified } \\
\text { peat with } \\
\text { pH } 5-6.5\end{array}$} & \multirow{2}{*}{$\leq 100$} & 23 & 156 & 0.42 & \multirow{4}{*}{2.0} \\
\hline & & 54.8 & 150 & 0.43 & \\
\hline & \multirow{2}{*}{$\leq 500$} & 23 & 162 & 0.31 & \\
\hline & & 54.8 & 152 & 0.31 & \\
\hline \multirow{4}{*}{$\begin{array}{c}\text { acidic peat } \\
\text { with pH } \\
3.5-4\end{array}$} & \multirow{2}{*}{$\leq 100$} & 23 & 160 & 0.36 & \multirow{4}{*}{11.8} \\
\hline & & 54.8 & 154 & 0.37 & \\
\hline & \multirow[t]{2}{*}{$\leq 500$} & 23 & 170 & 0.31 & \\
\hline & & 54.8 & 158 & 0.33 & \\
\hline
\end{tabular}

Bulk density is the ratio of the mass of dust to the volume occupied after free pouring (without kneading). Then dust was poured into it and the excess protruding above the upper edge was removed. The container filled with dust was weighed. The weight of the dust after free pouring into a container of known volume was obtained from the mass determinations.

\section{Analysis of results}

Having analysed the test results, it is impossible to determine unambiguously which of the tested dusts turned out to be the most dangerous as regards fire and explosion hazard. The de-acidified peat dust manifested susceptibility to self-ignition in the lowest temperature $150^{\circ} \mathrm{C}$ and $156^{\circ} \mathrm{C}$ depending on the volume of dust layer and grading. When the dust volume increased, self-ignition temperature was lower. This dependence applies to all the tested types of dust. It can be explained by the fact that less heat can be accumulated in thin layers of dust than in thick layers. The acidic peat dust was characterized by the largest moisture content of $11.8 \%$, which probably contributed to extending the time required for self-ignition. The lowest self-ignition temperature for that type of dust was $150^{\circ} \mathrm{C}$. The 
highest self-ignition temperature was observed for acidic peat dust in a temperature of $170^{\circ} \mathrm{C}$. De-acidified peat should be considered the most hazardous with respect to its propensity to self-heating. It was characterised by the lowest value of self-ignition temperature from among all tested samples $\left(150^{\circ} \mathrm{C}\right)$. It was achieved for the grading of $100 \mu \mathrm{m}$, basket number 2 (n2).

The moisture contents in this type of dust amounted to ca. $2 \%$. This was the lowest result from among all tested materials. As a rule the moisture content does not affect the value of self-ignition temperature, but only impacts the time until its achievement. In an analysis of selected types of ducts, the lowest self-ignition temperature was recorded for a dust with the lowest moisture contents. The highest moisture content was recorded for acidic peat dust. A result at the level of $11.8 \%$ was quite similar to the result declared by the manufacturer $(12 \%)$. Furthermore, this dust also achieved the highest value of selfignition temperature. The self-ignition temperature of this dust amounted to $170^{\circ} \mathrm{C}$ and has been achieved for the fraction of $\leq 500 \mu \mathrm{m}$ and basket volume of number $1(\mathrm{n} 1)$. A significant impact on the self-ignition temperature was exerted by the thickness of dust layer. For each of the tested materials differences have been recorded. In smaller baskets $\left(\mathrm{n} 1=23 \mathrm{~cm}^{3}\right)$ a higher self-ignition temperature was recorded than for bigger volumes $\left(\mathrm{n} 2=54.8 \mathrm{~cm}^{3}\right)$. This difference reached as much as $10^{\circ} \mathrm{C}$. This trend resulted from a bigger heat accumulation in thicker layers. A review of results allowed ascertaining that the size of fraction in tested dusts affects to a lesser extent the value of the self-ignition temperature. The smaller the particles, the lower the self-ignition temperature. This may be well seen during laboratory testing. On the other hand, in actual conditions, where dust comprises particles of different sizes, layers comprising smaller particle would become self-ignited much sooner. However, the grading does not affect significantly the rate at which selfignition temperature is achieved for the dusts we had selected for testing. Bulk density for de-acidified peat and for acidic peat was higher for smaller particles. Fewer pores have been recorded in the layer, because smaller particles better fill the space. The highest bulk density was recorded for dust of peat bricks, and the smallest mass per surface unit for the dust of acidic peat. Those results do not prove an important dependence between the value of bulk density and the value of self-ignition temperature. The studies have clearly shown that dusts tested in a small basket reached ignition much quicker than samples tested in larger amounts. For a basket with a capacity of $\mathrm{n} 1$ ignition took place after the lapse of less than two hours, and for the same type of dust tested in a basket of $\mathrm{n} 2$ after ca. 3 hours. The quickest ignition was noted for the dust of acidic peat. Already during the first hour of testing ignition was achieved in basket $\mathrm{n} 1$, and in basket $\mathrm{n} 2$ - up to the second hour of the experiment. Results have shown that the acidity level of combusted dust clearly affected the self-ignition temperature. The tested dust of acidic peat was found to have a self-ignition temperature by $6^{\circ} \mathrm{C}$ lower than the dust of de-acidified peat in the same conditions. The dust of de-acidified peat was the most dangerous type, as it was characterized by the lowest self-ignition temperature. This results from a necessity to control temperatures in places where dusts are stored. It means that particular caution is required in places where the tested dusts may deposit, and all actions should be undertaken to exclude self-heating that may initiate the self-ignition process and cause fire.

\section{Conclusion}

The following final conclusions may be drawn based on the conducted tests:

- the thicker the layer of accumulated peat dust, the lower the self-ignition temperature,

- the bigger the diameter of peat dust grains, the higher the self-ignition temperature,

- the more acidity of heated peat dust, the lower the self-ignition temperature,

- the thinner the layer of studied dusts, the quicker it becomes heated up, 
- the tested de-acidified peat dust was found to have the best self-heating propensity from among all the tested dusts,

- the acidic peat dust achieved the lowest self-ignition temperature for smaller particles $(\leq 100 \mu \mathrm{m})$ than the dust of peat bricks with the same particle size,

- the peat bricks dust achieved a lower self-ignition temperature for larger particles $(\leq 500$ $\mu \mathrm{m})$ than dust peat bricks with the same particle size.

The paper was carried out under research project no. DOBR-BIO4/050/13009/2013: Development of system solutions to support the execution of post-fire investigations based on cutting-edge technologies, including technical and IT tools, financed by the National Centre for Research and Development of Poland.

\section{References}

1. D. Drysdale, An introduction to fire dynamics, (3th edition, John Wiley and Sons, New York, 2011)

2. R.K Eckhoff., K. Rolf Dust Explosions in the Process Industries. (3rd ed. Gulf Professional Publishing, an imprint of Elsevier Science 2003)

3. M. Półka, E. Piechocka, B, Kukfisz, Przem. Chem. 91, 6 (2012)

4. B. Kukfisz, M. Półka, Z. Salamonowicz, M. Woliński, Przem. Chem. 92, 10 (2013)

5. M. Półka, Z. Salamonowicz, M. Woliński, B. Kukfisz, Elsevier Procedia Engin. 45, (2012)

6. R.K. Eckhoff., J. Loss Prevent. 19 (2006)

7. W. Kordylewski, T. Mączka, Archiwum Spalania 12, 1-2 (2012)

8. K. Lebecki, Zagrożenia pyłowe w górnictwie (Katowice 2004)

9. K. Lebecki, Zeszyty Naukowe WSZOP 1, 6 (2010)

10. S. Mannan, Lees' Loss Prevention in the Process Industries (Elsevier 2005)

11. EN 15188:2007 